\title{
Escolha do(a) Parceiro(a) Ideal por Heterossexuais: São seus Valores e Traços de Personalidade uma Explicação?
}

\author{
Choice of Ideal Partner by Heterosexuals: Are their Values \\ and Personality Traits an Explanation?
}

\author{
Ana Isabel A. S. de Brito Gomes, Valdiney Veloso Gouveia*, Nelson Aleixo da Silva Júnior, \\ Márcio de Lima Coutinho \& Layrtthon Carlos de Oliveira Santos \\ Universidade Federal da Paraíba, João Pessoa, Brasil
}

\begin{abstract}
Resumo
O presente estudo objetivou conhecer em que medida os valores humanos e os traços de personalidade se correlacionam com atributos desejáveis do(a) parceiro(a) ideal entre heterossexuais. Participaram 205 pessoas (100 mulheres e 105 homens) da população geral de João Pessoa (PB). Estes responderam aos seguintes instrumentos: Questionário dos Valores Básicos, Inventário dos Cinco Grandes Fatores e Escala de Atributos do Parceiro Ideal, além de perguntas sociodemográficas. Os valores se correlacionaram de forma teoricamente esperada com os atributos, sendo mais preponderantes do que os traços de personalidade. Quando comparados, homens e mulheres diferiram na importância dada a tais atributos. Finalmente, mostrouse adequado o modelo hierárquico traços de personalidade $\rightarrow$ valores $\rightarrow$ atributos. Estes resultados foram discutidos tomando como referência a perspectiva evolucionista da escolha de parceiro e a teoria funcionalista dos valores humanos.

Palavras-chave: Atributos, parceiro, relacionamento, valores, personalidade.
\end{abstract}

\begin{abstract}
This study aimed to know to which extent human values and personality traits are correlated with desirable attributes of an ideal partner among heterosexuals. Participants were 205 people (100 women and 105 men) from the general population of João Pessoa-PB, Brazil. They answered the following instruments: Basic Values Survey, Big Five Inventory, Attributes of Ideal Partner Scale as well as socio-demographic questions. The values were correlated in a theoretically expected way with the attributes of an ideal partner, being more relevant than the personality traits. When they were compared, men and women differed in the importance given to these attributes. Finally, the hierarchical model of personality traits $\rightarrow$ values $\rightarrow$ attributes showed to be adequate. The findings were discussed based on the evolutionary perspective on mate choices and the functionalist theory of human values.

Keywords: Attributes, partner, relationship, values, personality.
\end{abstract}

No campo dos relacionamentos íntimos, a busca do "verdadeiro amor" não costuma deixar qualquer pessoa de fora. De fato, a maioria das pessoas em algum momento de suas vidas procura ou espera uma "alma gêmea", existindo indícios de que 90\% das pessoas se casam ao menos uma vez na vida (Silva, 2006). Contudo, nas relações íntimas são admitidas diversas configurações, que transitam entre os de curta e longa duração (Matos, Férez-Carneiro, \& Jablonski, 2005). Considerando os tipos de relacionamentos e ao que estes se propõem, as pessoas costumam estabelecer padrões e regras de seleção de parceiro(a) que vão desde as exigências mais

\footnotetext{
* Endereço para correspondência: Centro de Ciências Humanas Letras e Artes, Campus I, Departamento de Psicologia, Cidade Universitária, s/n, Universidade Federal da Paraíba, João Pessoa, PB, Brasil 58051-900. Email: vvgouveia@gmail.com
}

superficiais ou a ausência destas, até àquelas que funcionam como condição para escolha de uma determinada pessoa para dar início a um relacionamento estável. É neste contexto que se busca um(a) parceiro(a) ideal, um "príncipe encantado" ou uma "mulher dos sonhos". Precisamente o interesse deste estudo é com este tipo de parceiro(a), isto é, aquele(a) que se presume ideal para um relacionamento duradouro. Interessa, especificamente, conhecer que atributos são desejáveis neste(a) parceiro(a) e como tais atributos se relacionam com os valores humanos e os traços de personalidade dos indivíduos que escolhem os referidos atributos. Compreender tais aspectos demanda situar as perspectivas teóricas nas quais se fundamenta este estudo.

\section{Teorias sobre a Escolha do(a) Parceiro(a)}

Não é de hoje que a temática da escolha do(a) parceiro(a) tem sido foco de atenção. Porém, enquanto obje- 
to de estudo no âmbito científico, esta tem se apresentado mais recente. Faz-se aqui um recorte de duas das principais disciplinas que buscam identificar e compreender padrões desta escolha: a Psicologia Social e a Psicologia Evolucionista.

Psicologia Social. A atração interpessoal é uma temática recorrente nesta área, funcionando como uma espécie de prelúdio de uma relação íntima (Sternberg, 2000), evidenciando características e contextos que podem fazê-la mais provável. Segundo Aronson, Wilson e Akert (2002), a proximidade funciona como um antecedente-chave da atração, tal como ocorre com a semelhança, que faz mais provável os parceiros se aproximarem (Berscheid \& Reis, 1998). Segundo Hatfield (1996), a atração física é também determinante da atração interpessoal, constituindo-se um orientador concreto neste tipo de relação. A propósito, em estudo realizado com 72 pares de estudantes, a atração física foi o fator principal na explicação da atração interpessoal (Aronson et al., 2002). Portanto, ao se falar em relacionamentos íntimos nesta perspectiva, há de se pensar em aspectos como proximidade, semelhança e atração física, que têm papéis fundamentais no surgimento da atração interpessoal.

Segundo Michener, DeLamater e Myers (2005), a atração inicial por uma pessoa é influenciada por normas sociais, atração física e processos de troca interpessoal, enfatizando que cada cultura especifica os tipos de relacionamento que as pessoas podem ter. Um exemplo disso se observa nas normas de homogamia ao indicar que os amigos, namorados e cônjuges sejam caracterizados pela semelhança de idade, raça, religião e status socioeconômico, onde diferenças em uma ou mais dimensões tornam uma pessoa mais ou menos adequada para algum tipo de relacionamento.

Swani e Furham (2008), em seu livro The Psychology of Physical Attraction, indicam que áreas distintas levantam questões diferentes sobre a atração física. Portanto, segundo pesquisadores desta área, os indivíduos são atraídos pelos outros por uma série de razões, onde a aparência física é apenas uma delas e, desta maneira, a atração física não pode ser separada do contexto social em que o relacionamento acontece. Conforme estes autores, a manifestação de padrões de atração física pode ser diferente em culturas distintas, mas os propósitos se assemelham. Seguramente, cada cultura pode possuir etiquetas e papéis sociais diferentes, porém a busca por determinadas características parece ser algo que transcende o contexto específico. Contudo, este aspecto parece ficar evidente na perspectiva a seguir.

Psicologia Evolucionista. Esta disciplina se interessa mais pela atração física per se do que ao processo de interação. Busca-se, então, compreender como certos traços e feições humanas são mais atraentes do que outros, sendo esta a abordagem teórica que mais tem chamado atenção dos pesquisadores nos últimos anos. Baseada em achados de Charles Darwin, esta disciplina admite que a natureza humana é constituída pela cultura e biologia, sendo as características anatômicas, neurocognitivas e comportamentais selecionadas segundo as pressões no processo de evolução humana (Confer et al., 2010). Deste modo, os comportamentos dos ancestrais do homem em sua prática primitiva influenciam na seleção de parceiros(as) nos dias de hoje (D. M. Buss, 2003).

Partindo deste entendimento, D. M. Buss (1989) investigou diversos aspectos da seleção sexual em 37 culturas de seis continentes e cinco ilhas $(n=10,047)$. Ele procurou identificar diferenças entre os sexos nas preferências que norteiam o relacionamento sexual humano, pressupondo que tais diferenças seriam universais, baseadas em concepções evolucionistas de investimento parental, seleção sexual, capacidade reprodutiva e assimetrias sexuais. Suas evidências foram de que as mulheres, em diferentes culturas, valorizaram o aspecto financeiro mais do que os homens; já estes, por sua vez, deram mais relevância a aspectos físicos da mulher.

D. M. Buss (2007) indica que homens e mulheres, baseados no histórico evolutivo da espécie e enfocando a função de cada sexo com vistas ao sucesso evolutivo, distinguem-se quanto ao processo de seleção de parceiros, onde cada um valoriza atributos diferentes no(a) outro(a). Por exemplo, mulheres valorizam atributos que direcionam sua busca reprodutiva ao seu sustento e dos filhos, enquanto os homens preferem atributos que direcionam sua busca ao sucesso reprodutivo por meio da excelência na fertilidade da possível parceira (Fisher 1995).

Em contexto brasileiro, corroborando os achados de D. M. Buss (1989, 2007), Féres-Carneiro (1997) detectou que dentre os atributos que apresentaram diferenças significativas, a qualidade jovem e fisicamente atraente foi mais importante para os homens nas condições amorosas variadas. Por outro lado, a capacidade econômica e a competência profissional foram mais valorizadas pelas mulheres como atributos de seus parceiros. Altafim, Luandos e Caramaschi (2009), em situação de envolvimento mais sério, observaram que as mulheres deram mais prioridade do que os homens aos critérios alto poder aquisitivo, popularidade e inteligência. Contrariamente, eles pontuaram mais nos atributos gentileza, compreensão, criatividade, inteligência e bom nivel de estudo. Portanto, sugere-se que as mulheres, no caso de relacionamentos duradouros, levam em conta o poder aquisitivo do parceiro, enquanto que os homens estão mais interessados no atributo de beleza física da mulher.

Em resumo, presumivelmente, a escolha de atributos de um(a) parceiro(a) ideal pode ser explicada por diversos fatores, como o sexo daquele que escolhe (Amélio, 2001; Borrione \& Lordelo, 2005; D. M. Buss \& Barnes, 1986; D. M. Buss \& Schmitt, 1993; Féres-Carneiro, 1997). Porém, é possível que não sejam apenas fatores biológicos (sexo masculino ou feminino) ou concretos (dinheiro, aparência) que determinarão tais escolhas. Considerando a preponderância de fatores de proximidade e semelhança, não somente física, mas também cultural, além da natureza eletiva da ação, é possível que características 
Gomes, A. I. A. S. B., Gouveia, V. V., Silva Júnior, N. A., Coutinho, M. L. \& Santos, L. C. O. (2013). Escolha do(a) Parceiro(a) Ideal por Heterossexuais: São seus Valores e Traços de Personalidade uma Explicação?

mais subjetivas da pessoa que escolhe possam ser relevantes, a exemplo de seus valores (Gouveia et al., 2010) e traços de personalidade (A. H. Buss, 1989; Ellis, Abrams, \& Abrams, 1995). Estes são os dois construtos de interesse no presente estudo, demandando que sejam tratados mais detidamente.

\section{Valores Humanos}

Embora exista uma compreensão mais ou menos comum acerca do que são os valores, têm sido elaboradas diferentes teorias que visam explicar seu conteúdo e estrutura (por exemplo, Inglehart, 1991; Rokeach, 1973; Schwartz, 1994). No presente caso, porém, considera-se um modelo específico, denominado Teoria funcionalista dos valores humanos, que tem reunido evidências de sua adequação no contexto brasileiro (Gouveia, 2003; Gouveia, Fonsêca, Milfont, \& Fischer, 2011). Esta compreende uma proposta integradora, embora parcimoniosa, que tem sido fundamentada (Gouveia, Milfont, Fischer \& Santos, 2008). São três seus pressupostos principais: (a) assume a natureza benevolente do ser humano; (b) admite que os valores são representações cognitivas das necessidades individuais, demandas da sociedade e institucionais, que restringem os impulsos pessoais e asseguram um ambiente estável e seguro; e (c) consideram como apropriado tratar os valores como terminais, ou seja, expressam um propósito si mesmos.

Gouveia (2003; Gouveia et al., 2008) identificou duas funções consensuais dos valores: (a) guiam as ações do homem (tipo de orientação; Schwartz, 1994) e (b) expressam cognitivamente suas necessidades (tipo de motivador; Inglehart, 1991). A primeira função pode ser representada por três tipos de orientação: pessoal, central e social, enquanto a segunda por dois tipos motivadores: materialista (pragmático) e humanitário (idealista). A ênfase em valores pessoais implica priorizar seus próprios interesses acima daqueles dos demais, ao passo que quando os valores sociais são endossados, sugere dar importância aos interesses da coletividade; os valores centrais são compatíveis com estes dois tipos de orientações, não se limitando à dicotomia pessoal-social, pois refletem as necessidades humanas mais básicas (sobrevivência) e elevadas (autorrealização). Priorizar valores materialistas implica uma orientação para metas específicas e regras normativas, enquanto endossar aqueles humanitários configura uma orientação baseada em ideias e princípios mais abstratos, coerentes com um espírito inovador e menos dependente de bens materiais. A combinação destas duas funções principais dos valores dá origem a seis subfunções valorativas, com valores específicos entre parênteses:

Existência. Reúne valores com orientação central, sendo compatíveis com aqueles pessoais e sociais, situando-se no domínio motivador materialista; o propósito principal de valores desta subfunção é assegurar as condições básicas de sobrevivência biológica e psicológica (estabilidade pessoal, saúde e sobrevivência).
Realização. Esta subfunção é formada por valores que expressam o motivador materialista, porém destacando a orientação pessoal. As pessoas orientadas por tais valores são focadas em realizações materiais e buscam a praticidade em decisões e comportamentos (êxito, poder e prestígio).

Normativa. Esta subfunção compreende uma orientação social, sendo focada em regras sociais, e um motivador materialista. Seus valores enfatizam a vida social, a estabilidade grupal e o respeito por símbolos e padrões culturais que prevaleceram durante anos (obediência, religiosidade e tradição).

Suprapessoal. Os valores desta subfunção apresentam orientação central e motivador humanitário. Reconhecidamente, os seres humanos possuem uma necessidade por informação (curiosidade) que os conduzem a uma melhor compreensão e domínio do mundo físico e social, refletindo valores desta subfunção (beleza, conhecimento e maturidade).

Experimentação. Representa o motivador humanitário, mas com uma orientação pessoal. Os valores que a integram favorecem a promoção de mudança e inovação na estrutura das organizações sociais, aspectos que são típicos em pessoas jovens ou criadas em contextos mais liberais (emoção, prazer e sexualidade).

Interativa. Nesta subfunção os valores representam as necessidades de pertença, amor e afiliação, promovendo o estabelecimento e a manutenção das relações interpessoais por parte do indivíduo. Representa o motivador humanitário, porém acentuando a orientação social (afetividade, apoio social e convivência).

Em resumo, como os atos de decidir e escolher são um produto, sobretudo, axiológico (Schwartz, 1994), justifica-se que esta teoria ofereça uma explicação para a escolha de atributos desejáveis de um(a) parceiro(a) ideal (Gouveia et al., 2010). Contudo, é provável que não seja a única explicação a respeito; talvez os traços de personalidade possam ser um construto importante para explicar tais escolhas, ao menos como variável desencadeadora dos valores (Rokeach, 1973). Descreve-se a seguir a perspectiva admitida sobre personalidade.

\section{Traços de Personalidade}

De acordo com D. P. Schultz e Schultz (2006), a personalidade é um agrupamento permanente e peculiar de características que podem mudar em resposta a situações diferentes. Diversas teorias e medidas foram elaboradas para entender a personalidade e suas dimensões, logrando-se um consenso relativo em torno do modelo dos cinco grandes fatores (big five), que tem sido replicado em diversos estudos, empregando instrumentos e métodos diferentes (John \& Srivastava, 1999). Portanto, parece adequado tê-lo em conta no presente estudo.

Este modelo representa a estrutura básica subjacente a todos os traços de personalidade. Pressupõe cinco dimensões diferentes da personalidade, derivadas a partir de análises fatoriais de diversos inventários e questionários 
elaborados com o fim de avaliar a personalidade normal. Costa e McCrae (1992) consideram os cinco grandes fatores (CGF) como tendências básicas com fundamento biológico, não sendo influenciadas diretamente pelo ambiente. Admite-se que existe uma maturação inerente à personalidade e, neste sentido, os traços funcionam mais propriamente como expressões dos caracteres biológicos humanos do que como resultado de experiências de vida (Pervin \& John, 2004).

Coerente com este modelo, estima-se a estrutura da personalidade em cinco grandes dimensões, as quais costumam ser representadas por suas respectivas iniciais, resultando no acrônimo $\boldsymbol{O}-\boldsymbol{C}-\boldsymbol{E}-\boldsymbol{A}-\boldsymbol{N}$ (Openness to experience, Conscientiousness, Extraversion, Agreeableness e Neuroticism). Embora na literatura sejam encontradas traduções um tanto diferentes, adota-se aqui a seguinte classificação (Benet-Martínez \& John, 1998): (O) abertura. Também chamado de "cultura", "imaginação" ou "intelecto", revela indivíduos curiosos, imaginativos e criativos, que se divertem com ideias novas e valores não-convencionais; (C) conscienciosidade. Também chamado "falta de impulsividade" ou "vontade", indica comportamentos que acentuam o sentido de organização, persistência, controle e motivação para alcançar objetivos altruísticos; (E) extroversão. Denomina-se também de "expansão", revelando pessoas sociáveis, ativas, falantes, otimistas e afetuosas; (A) agradabilidade. Correspondente à "amabilidade" e "sociabilidade", descrevendo pessoas que tendem a ser generosas, bondosas, afáveis, prestativas e altruístas; e, finalmente, $(\mathbf{N})$ neuroticismo. Também nomeado como "instabilidade emocional", indica indivíduos propensos a sofrimento psicológico, podendo apresentar ideias irreais, baixa tolerância à frustração e respostas de enfrentamento (coping) não adaptativas.

Em resumo, a presente pesquisa tem como objetivo principal conhecer em que medida os valores humanos e os traços de personalidade se correlacionam com atributos desejáveis do(a) parceiro(a) ideal entre heterossexuais. De forma complementar, visa (a) conhecer se há diferença na importância dos atributos ideais para a escolha de parceiros por homens e mulheres heterossexuais e (b) avaliar em que medida os valores humanos podem funcionar como mediadores da relação entre os traços de personalidade e a importância dada às dimensões de atributos desejáveis do(a) parceiro(a).

\section{Método}

\section{Delineamento e Hipótese}

Considerou-se um delineamento correlacional, tratando com dois conjuntos de variáveis: (a) antecedentes: os traços de personalidade e os valores humanos e (b) critério: atributos desejáveis do parceiro ideal. Levando em conta a natureza normativa e motivacional da escolha de parceiro (D. M. Buss, 2007), assim como a relação de antecedência dos traços de personalidade com respeito aos valores (Olver \& Mooradian, 2003; Rokeach, 1973), formulou-se a seguinte hipótese alternativa: $H_{l}$ : Os valores mediarão a relação entre os traços de personalidade e a importância dada aos atributos desejáveis do(a) parceiro(a) ideal.

\section{Participantes}

Participaram 205 pessoas (100 mulheres e 105 homens) de orientação heterossexual da população geral de João Pessoa, PB. Esta foi uma amostra de conveniência (não probabilística), sendo considerada adequada para os propósitos estatísticos, permitindo estimativa robusta das correlações entre as variáveis de interesse (Gouveia, Santos, \& Milfont, 2009) e testagem de modelos de mediação (Vittinghoff, Sen, \& McCulloch, 2009). Tomaram-se como critérios de inclusão (a) a concordância em participar voluntariamente do estudo e (b) a capacidade manifesta de saber ler e escrever, permitindo responder instrumentos autoaplicáveis. Consideraramse como critérios de exclusão: (a) ser homossexual e (b) ter idade inferior a 18 anos. Portanto, os participantes do estudo apresentaram idades entre 18 e 52 anos $(m=$ $24,4, D P=6,10)$, sendo a maioria solteira $(78 \%)$ e com ensino superior incompleto $(60 \%)$; entre as religiões professadas, majoritariamente foi indicada a católica $(40,5 \%)$. Os que indicaram ter um relacionamento fixo constituíram aproximadamente a metade dos participantes $(49,3 \%)$.

\section{Instrumentos}

Os participantes receberam um livreto constituído pelos seguintes instrumentos:

Questionário dos Valores Básicos (QVB). Elaborado em língua portuguesa, está formado por 18 itens que avaliam as seis subfunções valorativas anteriormente descritas (Gouveia et al., 2008): experimentação, realização, existência, suprapessoal, interativa e normativa. Com o propósito de respondê-los, o participante deve indicar o grau de importância que cada valor tem como um princípio-guia em sua vida, utilizando uma escala de resposta de sete pontos, variando de $\mathbf{1}=$ Totalmente não importante a $7=$ Extremamente importante. Medeiros (2011) apresenta evidências de sua validade fatorial e consistência interna, avaliada por meio de confiabilidade composta acima de 0,60 .

Inventário dos Cinco Grandes Fatores de Personalidade (ICGFP). Compreende uma adaptação da medida de Benet-Martínez e John (1998) para o contexto brasileiro (Moura-de-Andrade, 2008), estando formado por 44 itens estruturados em sentenças curtas, que são respondidos em escala de cinco pontos, variando de $\mathbf{1}=$ Discordo totalmente a $\mathbf{5}=$ Concordo totalmente. $\mathrm{Na}$ sua adaptação foram encontrados cinco fatores com valores próprios superiores a 1 , apresentando os seguintes alfas de Cronbach $(\alpha)$ : abertura $(\alpha=0,65)$, conscienciosidade $(\alpha=0,65)$, extroversão $(\alpha=0,75)$, agradabilidade $(\alpha=$ $0,69)$ e neuroticismo $(\alpha=0,75)$. 
Gomes, A. I. A. S. B., Gouveia, V. V., Silva Júnior, N. A., Coutinho, M. L. \& Santos, L. C. O. (2013). Escolha do(a) Parceiro(a) Ideal por Heterossexuais: São seus Valores e Traços de Personalidade uma Explicação?

Escala de Atributos do Parceiro Ideal (EAPI). Partiu da medida de D. M. Buss e Barnes (1986), estando formada por 56 itens que descrevem uma pessoa com quem se pretende casar ou ter uma vida em comum, sendo respondidos em escala de cinco pontos, variando de $\mathbf{1}=\mathrm{Nada}$ importante a $\mathbf{5}$ = Totalmente importante (Gouveia et al., 2010). Apresenta cinco componentes com valores próprios superiores a 1 , cujos alfas de Cronbach $(\alpha)$ foram como seguem: sociável $(\alpha=0,79$; tolerante, atenciosa, discreta, determinada, gentil, compreensiva, solidária, sensível, paciente, decidida, livre e cúmplice), tradicional $(\alpha=0,77$; de boa família, admirada, poderosa, religiosa, elegante, possui bens, saudável, bem sucedida, vigorosa e caseira), atlética $(\alpha=0,79$; sexy, sarada, boa forma, sensual e bonita), afetuosa ( $\alpha=0,74$; carinhosa, amável, companheira, alegre, amiga, apaixonada e acolhedora) e batalhadora ( $\alpha=0,63$; trabalhadora, corajosa, sincera, responsável e estudiosa).

Questionário Sociodemográfico. Os participantes também responderam perguntas que procuravam caracterizálos: idade, sexo, orientação sexual, religião, estado civil e nível de instrução, incluídas ao final do livreto.

\section{Procedimento}

A participação das pessoas foi individual, sendo abordadas em contextos de lazer (por exemplo, centro de vivências, espaços culturais, praças de alimentação), nos próprios domicílios ou em universidades públicas e privadas. Os participantes foram contatados e solicitados a participar voluntariamente da pesquisa, assinando previamente um termo de consentimento livre e esclarecido. A todos foi informado que suas respostas seriam tratadas de forma estatística, no conjunto, assegurando o anonimato de sua participação. A pesquisa foi aprovada pelo

Tabela 1
Comitê de Ética em Pesquisa com Seres Humanos, do Hospital Universitário Lauro Wanderley, Universidade Federal da Paraíba (Protocolo CEP/ HULW nº 257/10). Em média, 20 minutos foram suficientes para concluir a participação.

\section{Análise de Dados}

Os dados foram analisados com o pacote estatístico PASW (versão 19). Além de estatísticas descritivas (média, desvio padrão e frequência), úteis para a caracterização dos participantes da pesquisa, foram realizadas análises de variância (Anova, Manova), correlação $r$ de Pearson, teste $z$ para comparação de dois coeficientes de correlação interdependentes, regressão linear múltipla e teste de mediação de Sobel.

\section{Resultados}

Procura-se descrever a seguir os resultados em três partes. Primeiramente, comparam-se homens e mulheres quanto à importância dada aos atributos desejáveis do(a) parceiro(a) ideal; posteriormente, apresentam-se as correlações de valores e traços de personalidade com tais atributos; e, por fim, testam-se os modelos hierárquicos personalidade $\rightarrow$ valores $\rightarrow$ atributos $\left(H_{1}\right)$.

\section{Atributos do (a) Parceiro (a) Ideal em Função do Sexo}

Realizou-se uma Manova considerando como variável antecedente o sexo dos participantes e como variáveiscritério as cinco dimensões de atributos desejáveis do(a) parceiro(a) ideal, observando diferenças [Lambda de Wilks $\left.=0,80, F(5,174)=8,86, p<0,001, \eta^{2}=0,20\right]$. As estatísticas descritivas para cada grupo nas dimensões e os respectivos testes estatísticos são apresentadas na Tabela 1.

Importância Dada aos Atributos do(a) Parceiro(a) Ideal por Homens e Mulheres

\begin{tabular}{llllll}
\hline & \multicolumn{5}{c}{ Sexo } \\
\cline { 2 - 6 } & \multicolumn{2}{c}{ Masculino } & \multicolumn{2}{c}{ Feminino } \\
\hline Atributos Desejáveis & $M$ & $D P$ & $M$ & $D P$ & $F$ \\
\hline Afetuosa & 4,5 & 0,53 & 4,7 & 0,43 & $4,51^{*}$ \\
Atlética & 3,5 & 0,91 & 2,9 & 0,91 & $16,25^{* * *}$ \\
Sociável & 4,1 & 0,75 & 4,4 & 0,44 & $12,34^{* * *}$ \\
Tradicional & 3,6 & 0,82 & 3,9 & 0,62 & $7,61^{* *}$ \\
Batalhadora & 3,9 & 0,71 & 4,1 & 0,65 & $4,24^{*}$ \\
\hline
\end{tabular}

Notas. $* p<0,05, * * p<0,01, * * * p<0,001$ (teste bicaudal).

Ao comparar as pontuações nas dimensões de atributos em função do sexo, observou-se que os homens ( $m=3,5, D P=0,91)$ pontuaram mais do que as mulheres $(m=2,9, D P=0,91)$ unicamente na dimensão atlética $(F=16,25, p<0,001)$. Contrariamente, as mulheres $(m=4,7, D P=0,43)$ o fizeram em maior medida que os homens ( $m=4,5, D P=0,53)$ na dimensão sociável $(F=12,34, p<0,001)$; porém, nas outras três dimensões elas também apresentaram médias superiores: tradicional $(F=7,61, p<0,01)$, afetuosa $(F=4,51, p<$ $0,05)$ e batalhadora $(F=4,24, p<0,05)$. 
Valores, Traços de Personalidade e Atributos Desejáveis do(a) Parceiro(a) Ideal

Procurou-se correlacionar as subfunções valorativas e os cinco grandes traços de personalidade com a importância conferida aos atributos desejáveis do(a) parceiro(a) ideal, sendo os resultados apresentados na Tabela 2. Nesta também podem ser observados os coeficientes de consistência interna das medidas empregadas e o teste que compara os coeficientes de correlação para valores e traços de personalidade.

Tabela 2

Correlação de Valores e Traços de Personalidade com Atributos do(a) Parceiro(a) Ideal

\begin{tabular}{|c|c|c|c|c|c|c|c|}
\hline \multirow{2}{*}{\multicolumn{2}{|c|}{ Correlatos }} & \multicolumn{6}{|c|}{ Atributos desejáveis } \\
\hline & & $\alpha$ & Afetuosa & Atlética & Sociável & Tradicional & Batalhadora \\
\hline \multicolumn{8}{|c|}{ Subfunções valorativas } \\
\hline & Experimentação & 0,64 & $0,23 * * *$ & $0,35^{* * *}$ & $0,28 * * *$ & 0,10 & $0,23 * * *$ \\
\hline & Realização & 0,71 & $0,25 * * *$ & $0,31^{* * *}$ & $0,27 * * *$ & $0,16^{*}$ & $0,30 * * *$ \\
\hline & Existência & 0,66 & $0,34 * * *$ & $0,19^{* *}$ & $0,39 * * *$ & $0,33 * * *$ & $0,31 * * *$ \\
\hline & Suprapessoal & 0,45 & 0,13 & 0,10 & $0,19 * *$ & 0,06 & $0,18^{*}$ \\
\hline & Interativa & 0,60 & $0,39 * * *$ & 0,14 & $0,44 * * *$ & $0,39 * * *$ & $0,22 * *$ \\
\hline & Normativa & 0,70 & $0,30 * * *$ & 0,04 & $0,33 * * *$ & $0,47 * * *$ & $0,27 * * *$ \\
\hline \multicolumn{8}{|c|}{ Traços de Personalidade } \\
\hline & Abertura & 0,75 & 0,04 & 0,11 & 0,10 & $-0,09$ & 0,05 \\
\hline & Conscienciosidade & 0,68 & $-0,03$ & $-0,12$ & 0,04 & 0,13 & 0,06 \\
\hline & Extroversão & 0,73 & 0,12 & $0,15^{*}$ & $0,22 * *$ & $0,18 *$ & $0,16^{*}$ \\
\hline & Amabilidade & 0,40 & 0,04 & $-0,20 * *$ & 0,04 & 0,17 & $-0,08$ \\
\hline & Neuroticismo & 0,73 & $-0,03$ & $-0,04$ & $-0,03$ & $-0,09$ & $-0,04$ \\
\hline$r_{\text {médio }}$ & Valores & & 0,27 & 0,19 & 0,32 & 0,25 & 0,25 \\
\hline$r_{\text {médio }}$ & Personalidade & & 0,05 & 0,12 & 0,08 & 0,13 & 0,07 \\
\hline$\Delta r$ & & & $2,28 *$ & 0,71 & $2,53 * *$ & 1,24 & $1,86^{*}$ \\
\hline
\end{tabular}

Notas. ${ }^{*} p<0,05,{ }^{* *} p<0,01, * * * p<0,001$ (teste unicaudal; eliminação por pares de dados faltosos). $\Delta r=$ Corresponde a um valor de teste $t$ para dois coeficientes de correlação interdependentes, quando não há variável em comum.

No que se refere aos valores, percebe-se sua associação clara com a importância dada aos atributos do(a) parceiro(a) ideal. Procurando focar os resultados teórica e empiricamente mais consistentes $(p<0,001)$, destacamse as seguintes correlações: subfunção experimentação se correlacionou mais forte e diretamente com as dimensões atlética $(r=0,35)$ e sociável $(r=0,28)$; realização o fez com atlética $(r=0,31)$ e batalhadora $(r=0,30)$; existência se correlacionou com a importância dada a todas as dimensões, não apresentando um padrão nítido de discriminação; suprapessoal, contrariamente, foi a subfunção que menos se correlacionou com tais dimensões; a subfunção interativa apresentou maior correlação com sociável $(r=0,44)$; e, finalmente, normativa o fez com tradicional $(r=0,47)$.

Quanto aos traços de personalidade, observa-se nitidamente na Tabela 2 que eles têm menos a ver com a importância conferida aos atributos do(a) parceiro(a) ideal. Concretamente, apenas dois deles se correlacionaram com tais atributos, destacando-se extroversão, que o fez mais nitidamente com sociável $(r=0,22, p<0,01)$, e amabilidade, que se mostrou inversamente correlacionado com a dimensão atlética $(r=-0,20, p<0,01)$.
Por fim, avaliou-se em que medida os valores e os traços de personalidade poderiam contribuir diferentemente para explicar a importância dada aos atributos do(a) parceiro(a) ideal. Deste modo, para cada dimensão, procedeu-se à comparação das correlações com estes dois construtos $(\Delta r)$, observando diferença significativa em relação à afetuosa, sociável e batalhadora, com os valores compartilhando maior variância. De modo complementar, realizaram-se análises de regressão múltiplas, tomando cada dimensão de atributo como variável critério e, separadamente, as subfunções valorativas e os traços de personalidade como variáveis antecedentes. Os valores foram relevantes para explicar a importância atribuída a todos os atributos desejáveis do(a) parceiro(a) ideal $(F>$ $5, p<0,001)$, contribuindo com a explicação de 13 (batalhadora) a $25 \%$ (tradicional) da variância $\left(R_{\text {ajustado }}{ }\right)$. Por outro lado, dois dos atributos (afetuosa e batalhadora) não foram adequadamente explicados $(F<1,96)$, e o que o foi mais (atlética) alcançou $7 \%$ da variância.

\section{Modelo Hierárquico}

Como previamente foi constatado, os traços de personalidade parecem ter pouco a ver com a importância 
Gomes, A. I. A. S. B., Gouveia, V. V., Silva Júnior, N. A., Coutinho, M. L. \& Santos, L. C. O. (2013). Escolha do(a) Parceiro(a) Ideal por Heterossexuais: São seus Valores e Traços de Personalidade uma Explicação?

conferida aos atributos do(a) parceiro(a). Não obstante, hipotetizou-se uma relação dos valores com tais traços, que devem preceder aqueles $\left(H_{1}\right)$. Neste sentido, testa- ram-se modelos hierárquicos mais teoricamente prováveis, seguindo a estrutura personalidade $\rightarrow$ valores $\rightarrow$ atributos, avaliando o papel mediador dos valores. Os resultados são mostrados na Tabela 3.

Tabela 3

Mediação dos Valores entre Traços de Personalidade e Atributos Desejáveis

\begin{tabular}{llll}
\hline Atributo & Relação A $\rightarrow \mathrm{B}$ & Relação B $\rightarrow \mathrm{C}$ & $Z$ de Sobel \\
\hline \multirow{3}{*}{ Atlética } & Extroversão $\rightarrow$ Experimentação & Experimentação $\rightarrow$ Atlética & \\
& $a=0,30$ & $b=0,30$ & $2,50^{*}$ \\
& $S_{a}=0,105$ & $S_{b}=0,058$ & \\
Tradicional & Conscienciosidade $\rightarrow$ Normativa & Normativa $\rightarrow$ Tradicional & $3,68^{* *}$ \\
& $a=0,60$ & $b=0,25$ & \\
Afetuosa & $S_{a}=0,141$ & $S_{b}=0,034$ & $2,47^{*}$ \\
& Agradabilidade $\rightarrow$ Interativa & Interativa $\rightarrow$ Afetuosa & \\
Sociável & $a=0,34$ & $b=0,19$ & $3,15^{* *}$ \\
& $S_{a}=0,125$ & $S_{b}=0,032$ & \\
& Abertura $\rightarrow$ Experimentação & Experimentação $\rightarrow$ Sociável & \\
Batalhadora & $a=0,54$ & $b=0,16$ & $S_{b}=0,039$ \\
& $S_{a}=0,110$ & Realização $\rightarrow$ Batalhadora & \\
& Extroversão $\rightarrow$ Realização & $S_{b}=0,039$ & \\
\hline
\end{tabular}

Notas. $a=$ coeficiente de regressão não-padronizado para a associação entre a variável antecedente e a variável mediadora; $S_{a}=$ erro padrão de $a ; b=$ coeficiente de regressão não-padronizado para a variável mediadora e a variável critério; $S_{b}=$ erro padrão de $b$. $* p<0,05, * * p<0,01$.

Coerentemente com o hipotetizado, os valores mediam a relação entre os traços de personalidade e os atributos desejáveis do(a) parceiro(a) ideal. Especificamente, o teste de Sobel mostrou que experimentação mediou à relação entre o traço extroversão e a dimensão atlética $(z=2,50$, $p<0,05)$; normativa o fez em relação ao traço conscienciosidade e o atributo tradicional $(z=3,68, p<$ 0,01 ); a subfunção interativa mediou a relação do traço agradabilidade com os atributos de afetuosa $(z=2,47, p$ $<0,05)$; experimentação também mediou a relação entre abertura e sociável $(z=3,15, p<0,01)$; e, finalmente, realização se mostrou mediar a relação entre o traço de extroversão e o atributo batalhadora $(z=2,41, p<0,01)$.

\section{Discussão}

Em relação à importância dada às dimensões dos atributos desejáveis segundo o sexo, os resultados apresentam diferenças que são consistentes com os achados da Psicologia Evolucionista. Concretamente, os homens apreciam atributos que enfocam qualidades reprodutivas das mulheres (atlética), enquanto estas apreciam atributos mais relacionados com os cuidados que os homens podem apresentar com elas e seus descendentes (afetuosa, sociável e tradicional; D. M. Buss, 1989, 2007; D. M. Buss \& Barnes, 1986; Kenrick, Sadalla, Groth, \& Trost, 1990). Contudo, apesar de observar diferença quanto a atributos que se referem à possibilidade de ganho, recursos e bens materiais, esperava-se que a dimensão correspondente (batalhadora) fosse mais pronunciadamente endossada por mulheres (Borrione \& Lordelo, 2005; Gouveia et al., 2010), mas isso não ocorreu. Este achado precisará maior atenção, uma vez que D. M. Buss (1989) descreve esta como uma característica principal que diferencia os sexos na maioria das culturas. Talvez, no caso do contexto em que o estudo foi realizado (João Pessoa, PB), com as pessoas apresentando uma orientação mais materialista, ou seja, uma cultura caracterizada por um histórico de maior escassez e com valores mais pautados no aqui e agora, com necessidades mais imediatas (por exemplo, saúde e sobrevivência; Gouveia, 1998), a dimensão que enfoca elementos de realização as diferencie menos. Neste caso, caberia no futuro testar esta conjetura, considerando contextos diferentes de escassez ou realização.

No que se refere aos correlatos dos atributos do(a) parceiro(a) ideal, parece evidente o papel dos valores humanos como princípios que guiam as escolhas (Gouveia, 2003; Gouveia et al., 2008; Rokeach, 1973). As subfunções centrais têm papel interessante, no sentido de o tipo de escolha se fundamentar em princípios de existência, mas não tanto naqueles suprapessoais; provavelmente escolher alguém com quem se casar, que seja ideal, significa garantir a convivência, mas, sobretudo, a sobre- 
vivência em uma cultura materialista, pragmaticamente orientada em razão da escassez (Gouveia, 1998). No caso das subfunções que cumprem orientações pessoais, experimentação e realização parecem promover buscas por atributos práticos nos(as) parceiros(as), como podem ser representados, respectivamente, pelas dimensões atlética, que destaca a sensualidade, o prazer e o corpo, e batalhadora, que assinala os ganhos, a realização e o poder. Por outro lado, em se tratando dos valores sociais, as subfunções interativa e normativa promovem buscas por pessoas que apresentem atributos afetiva e tradicional, respectivamente, provavelmente ressaltando o princípio de similaridade, como estudado em Psicologia Social. Estes achados são congruentes com os anteriormente observados com base na teoria funcionalista dos valores humanos (Gouveia et al., 2010).

Com respeito aos traços de personalidade, embora se estime sua importância para compreender a escolha do(a) parceiro(a), sobretudo quando envolve um relacionamento em longo prazo (A. H. Buss, 1989), pareceu ser menos preponderante nesta pesquisa. Coube ao traço extroversão o principal papel explicador da presumível escolha, porém, inclusive neste caso, menos evidente do que a contribuição dos valores humanos. Neste sentido, os achados vão na direção do que propunha Rokeach (1973), sugerindo serem os valores aspectos centrais no sistema cognitivo das pessoas, influenciando suas atitudes e escolhas. Quiçá os traços de personalidade sejam características mais próprias das pessoas, estando enraizados como descritores de sua forma de ser no mundo; por outro lado, os valores podem ter mais a ver com as escolhas cotidianas, uma vez que se apresentam como princípiosguia na vida (Gouveia et al., 2008). Neste âmbito, vale ressaltar o papel mediador dos valores, servindo de conexão entre os elementos mais pessoais (traços de personalidade) e a importância conferida aos atributos do(a) parceiro(a) com quem construir uma vida.

\section{Considerações Finais}

O presente estudo procurou conhecer a relação entre os atributos desejáveis do(a) parceiro(a) ideal com os traços de personalidade e valores e, além disso, se homens e mulheres heterossexuais se diferenciam em relação à importância dada a tais atributos. Pretendeu, ainda, avaliar se os valores poderiam mediar a relação entre os traços de personalidade e a importância conferida a esses atributos. Confia-se que estes objetivos tenham sido alcançados, a partir dos resultados anteriormente descritos. Entretanto, não se descartam limitações da pesquisa, como, por exemplo, a amostra reduzida e de conveniência de participantes e a inclusão unicamente de medidas de autorrelato que, segundo a literatura, é dotada de vieses inerentes, de modo que as pessoas podem dissimular suas respostas estrategicamente a fim de demonstrar o que consideram socialmente desejável (Schmitt \& Steyer, 1993). Porém, considerando a consistência dos resulta- dos com o que estabelece a literatura, parece evidente sua contribuição, principalmente ao mostrar que os construtos personalidade e valores, embora estreitamente relacionados (Rokeach, 1973), apresentam diferenças conceituais e práticas, como evidenciadas quando considerado um elemento externo: atributos do(a) parceiro(a) ideal.

Confia-se que o presente artigo ofereça uma contribuição à literatura em Psicologia no Brasil, que tem oferecido ensaios e achados importantes a respeito das relações íntimas ou atratividade interpessoal (Babo \& Jablonski, 2002; Féres-Carneiro, 1997; Matos et al., 2005). Vale a pena destacar que esta temática, no geral, tem sido predominantemente fundamentada em perspectiva leiga, voltada para autoajuda, sem qualquer embasamento teórico-científico (Alferes, 2000; D. M. Buss, 2003).

Por fim, quanto a pesquisas futuras, é preciso pensar na escolha do(a) parceiro(a) não apenas entre adolescentes e jovens adultos; observações diárias dão conta de casamentos tardios e pessoas que, em razão de separação ou viuvez, decidem reconstituir família. É importante, portanto, procurar compreender a importância dada a atributos de um(a) parceiro(a) por parte destas pessoas. Isto é, buscar conhecer o que elas gostariam de encontrar em seu(sua) futuro(a) parceiro(a) e que importância os seus valores teriam a respeito. Estas são questões relevantes, considerando-se, sobretudo, a taxa crescente de divórcios e casamento registrada no contexto brasileiro (Instituto Brasileiro de Geografia e Estatística [IBGE], 2008). Esta questão parece ganhar maior importância quando se considera a relação entre valores e atributos desejáveis, admitindo que as prioridades axiológicas das pessoas podem mudar com os anos e em razão de papéis sociais assumidos (Rokeach, 1973).

\section{Referências}

Alferes, V. R. (2000). Atração interpessoal, sexualidade e relações íntimas. In J. Vala \& M. B. Monteiro (Eds.), Psicologia Social (pp. 125-158). Lisboa, Portugal: Fundação Calouste Gulbenkian.

Altafim, E. R. P., Luandos, J. M., \& Caramaschi, S. (2009). Seleção de parceiros: Diferenças entre gêneros em diferentes contextos. Psicologia Argumento, 27, 117-129.

Amélio, A. (2001). O mapa do amor: Tudo o que você queria saber sobre o amor e ninguém sabia responder. São Paulo, SP: Gente.

Aronson, E., Wilson, T. D., \& Akert, R. M. (2002). Psicologia social. Rio de Janeiro, RJ: LTC.

Babo, T., \& Jablonski, B. (2002). Folheando o amor contemporâneo nas revistas femininas e masculinas. Alceu, 4, 36-53.

Benet-Martínez, V., \& John, O. P. (1998). Los cinco grandes across cultures and ethnic groups: Multitrait-multimethod analyses of the big five in Spanish and English. Journal of Personality and Social Psychology, 75, 729-750.

Berscheid, E., \& Reis, H. T. (1998). Attraction and close relationships. In D. T. Gilbert, S. T. Fiske, \& G. Lindzey (Eds.), The handbook of social psychology ( ${ }^{\text {th }}$ ed., pp. 193281). New York: McGraw-Hill. 
Gomes, A. I. A. S. B., Gouveia, V. V., Silva Júnior, N. A., Coutinho, M. L. \& Santos, L. C. O. (2013). Escolha do(a) Parceiro(a) Ideal por Heterossexuais: São seus Valores e Traços de Personalidade uma Explicação?

Borrione, R. T., \& Lordelo, E. R. (2005). Escolha de parceiros sexuais e investimento parental: Uma perspectiva desenvolvimental. Interação em Psicologia, 1, 35-43.

Buss, A. H. (1989). Personality as traits. American Psychologist, 44, 1378-1388.

Buss, D. M. (1989). Sex differences in human mate preferences: Evolutionary hypotheses tested in 37 cultures. Behavioral and Brain Sciences, 12, 1-49.

Buss, D. M. (2003). The evolution of desire: Strategies of human mating. New York: Basic Books.

Buss, D. M. (2007). The evolution of human mating. Acta Psychologica Sinica, 39, 502-512.

Buss, D. M., \& Barnes, M. (1986). Preferences in human mate selection. Journal of Personality and Social Psychology, 50, 559-570.

Buss, D. M., \& Schmitt, D. P. (1993). Sexual strategies theory: An evolutionary perspective on human mating. Psychological Review, 100, 204-232.

Confer, J. C., Easton, J. A., Fleischaman, D. S., Goetz, C. D., Lewis, D. M. G., Perilloux, C., et al. (2010). Evolutionary psychology: Controversies, questions, prospects, and limitations. American Psychologist, 65, 110-126.

Costa, P. T., \& McCrae, R. R. (1992). The five-factor model of personality and its relevance to personality disorders. Journal of Personality Disorders, 6, 343-359.

Ellis, A., Abrams, M., \& Abrams, L. D. (2009). Personality theories: Critical perspectives. Beverly Hills, CA: Sage.

Féres-Carneiro, T. (1997). A escolha amorosa e interação conjugal na heterossexualidade e na homossexualidade. Psicologia: Reflexão e Crítica, 10, 351-368.

Fisher, H. (1995). Anatomia do amor: História natural da monogamia, do adultério e do divórcio. Rio de Janeiro, RJ: Eureka.

Gouveia, V. V. (1998). La naturaleza de los valores descriptores del individualismo y del colectivismo: una comparación intra e intercultural. (Unpublished doctoral dissertation). Departamento de Psicologia Social, Universidade Complutense de Madri, Espanha.

Gouveia, V. V. (2003). A natureza motivacional dos valores humanos: Evidências acerca de uma nova tipologia. Estudos de Psicologia (Natal), 8, 431-444.

Gouveia, V. V., Fonsêca, P. N., Gouveia, R. S., Diniz, P. K. C., Cavalcanti, M. F. B., \& Medeiros, E. D. (2010). Correlatos valorativos de atributos desejáveis de um (a) parceiro (a) ideal. Psicologia: Reflexão e Crítica, 23, 166-175.

Gouveia, V. V., Fonsêca, P. N., Milfont, T. L., \& Fischer, R. (2011). Valores humanos: Contribuições e perspectivas teóricas. In C. V. Torres \& E. R. Neiva (Eds.), A psicologia social: Principais temas e vertentes (pp. 296-313). Porto Alegre, RS: ArtMed.

Gouveia, V. V., Milfont, T. L., Fischer, R., \& Santos, W. S. (2008). Teoria funcionalista dos valores humanos. In M. L. M. Teixeira (Ed.), Valores humanos e gestão: Novas perspectivas (pp. 47-80). São Paulo, SP: Serviço Nacional de Aprendizagem Comercial.

Gouveia, V. V., Santos, W. S., \& Milfont, T. L. (2009). O uso da estatística na avaliação psicológica: Comentários e considerações práticas. In C. S. Hutz (Ed.), Avanços e polêmicas em avaliação psicológica: Em homenagem a Jurema Alcides Cunha (pp. 127-155). São Paulo, SP: Casa do Psicólogo.

Hatfield, E., \& Sprecher, S. (1996). Men's and women's preferences in marital partners in the United States, Russia, and Japan. Journal of Cross-Cultural Psychology, 26, 728-750.
Inglehart, R. (1991). El cambio cultural en las sociedades industriales avanzadas. Madri, España: Centro de Investigaciones Sociológicas Siglo XXI.

Instituto Brasileiro de Geografia e Estatística. (2008). Estatística do Registro Civil 2008. Retrieved August, 2010, from http://www.ibge.gov.br/home/estatistica/populacao/registrocivil/2008/default.shtm

John, O. P., \& Srivastava, S. (1999). The big-five trait taxonomy: History, measurement and theoretical perspectives. In L. Pervin \& O. P. John (Eds.), Handbook of personality: Theory and research ( $2^{\text {nd }}$ ed., pp. 102-138). New York: Guildford Press.

Kenrick, D. T., Sadalla, E. K., Groth, G., \& Trost, M. R. (1990). Evolution, traits and stages of human courtship: Qualifying the parental model. Journal of Personality, 58, 97-116.

Matos, M. S., Féres-Carneiro, T., \& Jablonski, B. (2005). Adolescência e relações amorosas: Um estudo sobre jovens das camadas populares. Interação, 22, 133-141.

Medeiros, E. D. (2011). Teoria Funcionalista dos Valores Humanos: Testando sua adequação intra e interculturalmente. (Tese de Doutorado não-publicada). Departamento de Psicologia, Universidade Federal da Paraíba, João Pessoa, PB.

Michener, H. A., DeLamater, J. D., \& Myers, D. J. (2005). Psicologia social. São Paulo, SP: Pioneira Thomson Learning.

Moura-de-Andrade, J. (2008). Evidências de validade do inventário dos cinco grandes fatores de personalidade para o Brasil. (Tese de Doutorado não-publicada). Departamento de Psicologia Social e do Trabalho, Universidade de Brasília, DF.

Olver, J. M., \& Mooradian, T. A. (2003). Personality traits and personal values: A conceptual and empirical integration. Personality and Individual Differences, 35, 109-125.

Pervin, L. A., \& John, O. P. (2004). Personalidade: Teoria e pesquisa. Porto Alegre, RS: Artmed.

Rokeach, M. (1973). The nature of human values. New York: Free Press.

Schmitt, M. J., \& Steyer, R. (1993). A latent state-trait model (not only) for social desirability. Personality and Individual Differences, 14, 519-529.

Schultz, D. P., \& Schultz, S. E. (2006). Teorias da personalidade. São Paulo, SP: Thompson Learning.

Schwartz, S. H. (1994). Are there universal aspects in the structure and contents of human values? Journal of Social Issues, 50, 19-45.

Silva, A. M. (2006). O conteúdo da vida amorosa de estudantes universitários. Interação em Psicologia, 10, 301-312.

Sternberg, R. J. (2000). Atração interpessoal. In J. Vala \& M. B. Monteiro (Eds.), Psicologia Social (4. ed., pp. 330-370). Lisboa, Portugal: Fundação Calouste Gulbenkian.

Swami, V., \& Furnham, A. (2008). The psychology of physical attraction. London: Routledge.

Vittinghoff, E., Sen, S., \& McCulloch, C. E. (2009). Sample size calculations for evaluating mediation. Statistics in Medicine, 28, 541-557. 
O Conselho Editorial comunica dois erros no Volume 26(1) 2013. No artigo "Escolha do (a) Parceiro (a) Ideal por Heterossexuais:São seus Valores e Traços de Personalidade uma Explicação?", o sobrenome de um dos autores está errado. Onde lia-se Layrtthon Carlos de Oliveira Campos, leia-se Layrtthon Carlos de Oliveira Santos. No artigo "Avaliação do funcionamento cognitivo por meio do CAT-A: evidências de validade", na página $44,3^{\circ}$ parágrafo, $2^{a}$ linha, onde lia-se $(P=0,000)$, leia-se $(p<0,001)$. 